Short Communication

\title{
Synthesis of Porous Carbon by Activation Method and its Electrochemical Performance
}

\author{
Wang Kai ${ }^{*}$, Zhou Shengzhe, Zhou Yanting, Ren Jun, Li Liwei, Lan Yong \\ College of Electrical Engineering, Qingdao University, Qingdao, 266071, China \\ E-mail: wkwj888@163.com
}

doi: $10.20964 / 2018.11 .30$

Received: 19 July 2018/ Accepted: 30 August 2018 / Published: 1 October 2018

For potential applications in supercapacitors, Porous carbon has been synthesized by the facile and economic activation method. The SEM and XRD are adopted to analyze the microstructure and the specific surface area. The material was tested as the electrode material for supercapacitors. With the increase of resin content, the specific capacitance of porous carbon increases gradually. When polyvinylbutyral in the compounds is $80 \%$, the specific capacitance is $201.9 \mathrm{~F} / \mathrm{g}$, and capacitance rentention rate is $93.38 \%$ for 500 cycles. The compounds may have a good prospect in supercapacitors.

Keywords: porous carbon, specific capacitance, activation method, electrochemical, supercapacitor

\section{FULL TEXT}

(C) 2018 The Authors. Published by ESG (www.electrochemsci.org). This article is an open access article distributed under the terms and conditions of the Creative Commons Attribution license (http://creativecommons.org/licenses/by/4.0/). 